\title{
Stocking Density Affects Diet Selection
}

\author{
By Doug Peterson, Mark Brownlee, and Tim Kelley
}

\section{On the Ground}

- Stocking density is a powerful tool to manage grazing land resources, as demonstrated on prairie and pasture in Missouri.

- Utilizing different stock densities, we can achieve different goals, including affecting diet selection, weed and brush control, improving utilization and manure distribution, and even improving seed-tosoil contact.

- We allow sufficient recovery periods between grazing events to increase plant diversity and develop as much above- and below-ground biomass as possible.

- During grazing periods we use stocking density to manipulate the amount of forage trampling that occurs.

- Trampling can have a very positive impact on water and mineral cycles, building soil and increasing fertility in our perennial grasslands.

Keywords: high stocking density, soil health, livestock diet selection, water cycle, and mineral cycle.

Rangelands 35(5):62-66

doi: 10.2111/RANGELANDS-D-13-00020.1

(C) 2013 The Society for Range Management

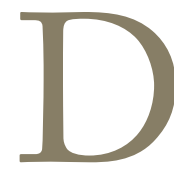
oes stocking density affect diet selection? To some that is a question that would require much research, thought, and study. Based on my experience as a grazier in Missouri, that is a nobrainer. Of course, stocking density has a profound effect on diet selection as well as livestock performance and plant species diversity and even affects water and mineral cycles. The thoughts and opinions in this article come from years of hands-on, real-world, make-it-or-break-it, farm experience with different size herds, different forages, and different management styles.

In addition to my own personal experiences, I have had the great fortune of working with many producers who have used a wide variety of grazing management styles and methods. For this article I enlisted the help of two very good friends, Tim Kelley and Mark Brownlee, who are both very experienced graziers, also from Missouri. But, more importantly than that, they are both incredibly observant. I don't know anyone who spends as much time walking around in, looking at, and contemplating their pastures as these two gentlemen do. Many times I have relied on their ideas and judgment when making decisions about my own operation.

We all ranch in areas that typically receive 35-38 inches of rainfall per year. Our forages are primarily cool season grasses such as tall fescue (Lolium arundinaceum), smooth brome (Bromus inermis Leyss.), orchard grass (Dactylis glomerata L.), and timothy (Phleum pratense L.), but we all have some warm season grasses such as big bluestem (Andropogon gerardii Vitman), Indiangrass (Sorghastrum nutans [L.] Nash), and switchgrass (Panicum virgatum L.) mixed into some of our pastures.

\section{How Does Stocking Density Affect Diet Selection?}

I have stood and watched cattle graze across a field picking out certain plants. I have walked beside them and watched them select certain plant parts. There is no doubt in my mind that cattle have preferences and dislikes. Between Mark Brownlee, Tim Kelley, and myself we have used many management styles with stocking densities of 1,000 to 500,000 pounds per acre and just about everything in between. In this article, we use the term "stocking density" to mean animal live weight on a per acre basis per grazing period. The grazing period could be anything from a few days to a few hours. There are many descriptive terms used for different stocking densities. We consider stocking densities below 50,000 pounds per acre to be more typical of management-intensive grazing $(\mathrm{MiG})^{1}$, stocking densities between 50,000 and 250,000 pounds per acre as high stocking densities (HSDs), and 250,000 pounds and up as ultra-high stocking densities (UHSDs). The three of us all agree that stocking density is one of the most important tools of livestock and forage management. At the levels we most commonly use (50,000-250,000 pounds per acre) the livestock over time can become pretty aggressive in their grazing habits. What makes them so aggressive that it will 
actually change their diet selection? I think that two things have a significant influence on their diet selection: becoming familiar with forages that they have not been required to eat before and being in such a confined environment that they have to compete with their herd mates for the next bite of grass.

Humans have trained many species of animals for a variety of purposes over thousands of years. Many of the training methods involve some type of force-breaking of an animal to do the desired task. The trick is to get them to do the desired task without being so hard on them that we hurt them physically or emotionally. When we hold cattle in an area much smaller than they are used to we are training them to do several things: to get used to being very close to their herd mates all of the time; to allow humans to be close to them quite a bit of the time; to eat things that many times they have never eaten before; and to eat when they are moved, even if they are already full.

Cattle that are managed at a low stocking density for their entire life and have adequate forage available become fairly selective about what they eat. Over the course of several generations this can lead to the selection of animals that will not eat certain species of plants even though those species are adequately palatable and nutritious.

When we first introduce cattle to a higher stocking density, they will graze the plants they prefer first, leaving the ones they dislike or that they are not familiar with. Under our higher stocking density strategy, if the appropriate paddock size is used, the livestock will be required to eat some of the forage they disliked or were not familiar with to meet their nutritional requirement. This is just a form of force training them to eat from all the plants in the paddock. Over a very short period either livestock will learn to eat a much wider variety of the species in the paddock or they will go hungry. There are others, including Kathy Voth at Livestock for Landscapes, ${ }^{i}$ who are promoting a training method that will train livestock to eat just about any plant. That is basically what we are doing. We just don't use an attractant to get them to eat the unfamiliar plants; we use short-term hunger.

Just like humans, livestock have their own personal space. If a human or another animal invades that space, it will stress them. If you take a herd of cows used to a very low stocking density of, say, 1,000 pounds to the acre and put them in a situation of 300,000 pounds to the acre, they will be visibly unsettled and nervous. Assuming you can hold them in the smaller area without them breaking the fence down, most cows will eventually become used to the new stocking density over the course of several days. Notice that I said most but not all.

In addition to our own livestock we take in 200-300 custom contract cow/calf pairs for a 6-month grazing period

'For more on Livestock for Landscapes see www.livestockforlandscapes. com. every May through October. Over the last several years we have grazed cows that came from Iowa, Nebraska, Kansas, Missouri, and Texas. When they arrive we typically put these cattle through a training period where we start them out at a low or moderate stocking density, and over time we increase that density until we get to the planned level. Most cattle adjust and accept this "training" fairly well. This past year we took in a set of contract cows that must have been born and raised in the wilds of Texas. Those Texas cows never did "settle down." We could keep them in the correct paddock most of the time at densities of up to 100,000 pounds per acre, but at stocking densities over that many of them were just unmanageable. They just couldn't take the pressure of another strange animal invading their space or of a human that close to them. Any nutritionist will tell you that putting physical stress on an animal will make them alter their food intake patterns. The cattle performed satisfactorily as long as we were paying attention, but, to me, this was a case of how stocking density clearly could negatively affect their diet selection and performance.

\section{How Does Stocking Density Affect Livestock Performance?}

Animal performance is usually more important than stocking density. Animal performance should normally not be sacrificed to gain higher stock density or impact to the land. We always have to be very aware of the class of livestock we are running, their nutritional needs, and the quality of the forage they are eating. When we increase stocking density to high levels we can create such a competition for forage that the livestock will eat the thatch off of the ground and the bark off of the trees. We must ensure that the forage availability is equal to or greater than the forage demand. Any time we create an environment that causes animals to eat something that doesn't meet their nutritional requirements we are going to have major problems.

Knowing that we are creating an environment where cows may graze less palatable forage, we must maintain a balance between stocking density and animal performance. If longterm animal performance is not maintained or improved, we are doing something wrong. However, there are times when we can use livestock, for short periods of time, as a tool to impact the land in a planned manner that may not always be good for the livestock's highest level of performance.

How do we maintain high stocking density and high animal performance? We have to make sure that even in a high stocking density environment we allow enough animal selectivity over the course of every day for each animal to take in the forage quality and quantity needed to meet their requirements. A stocking density of 80,000 pounds can still allow a high level of animal selectivity (Figs. 1 and 2). The cattle harvested all the leaves but left the majority of the stems of almost all forage species. If we are using multiple moves per day, cows will have a full spectrum of plant diversity put before them at each move. The more moves that there are each 


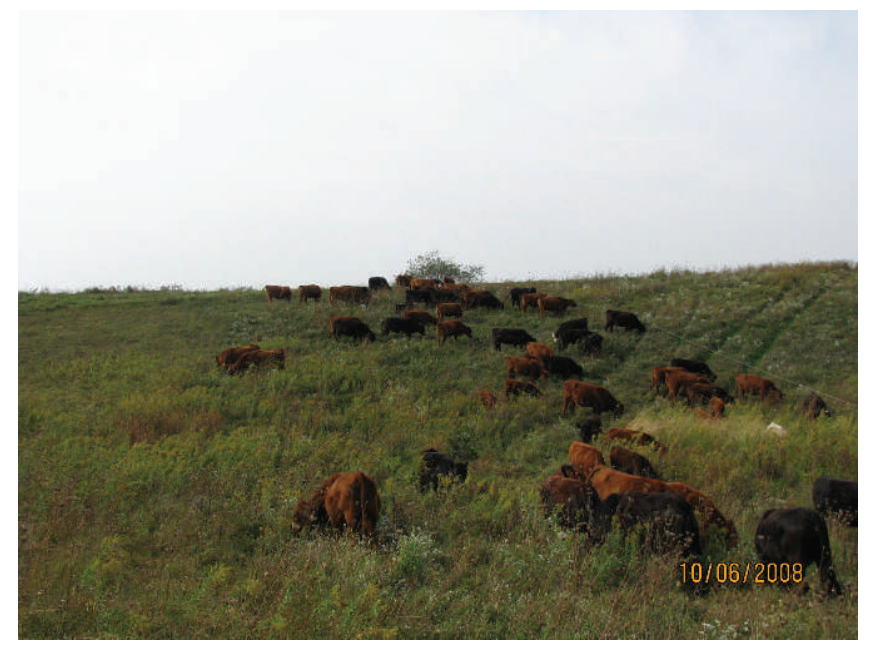

Figure 1. 80,000 stocking density with a lot of plant diversity for a north Missouri pasture.

day, the more opportunities there are for each cow to balance her diet. If we have some grazable forage remaining after the livestock are removed, we know that we provided enough forage for that grazing event. When Mark rotates his cattle out of a pasture his target is typically $60 \%$ of the forage eaten, $20 \%$ trampled, and 20\% remaining standing. By leaving something standing that the livestock could have eaten, there is less of a possibility that animals decreased their intake and hurt performance. Maintaining animal performance must be a crucial part of any high stocking density plan.

\section{Can You Manipulate Stock Density to Spread Utilization to Unpalatable Forage Species?}

In our tallgrass systems, high stocking density is an excellent tool to provide animal impact on nearly every plant in the pasture if that is desired. Our experience is that stocking densities of around 350,000 pounds per acre and above significantly reduce the cows' ability to selectively graze, with almost every plant in a paddock either bitten off or trampled.

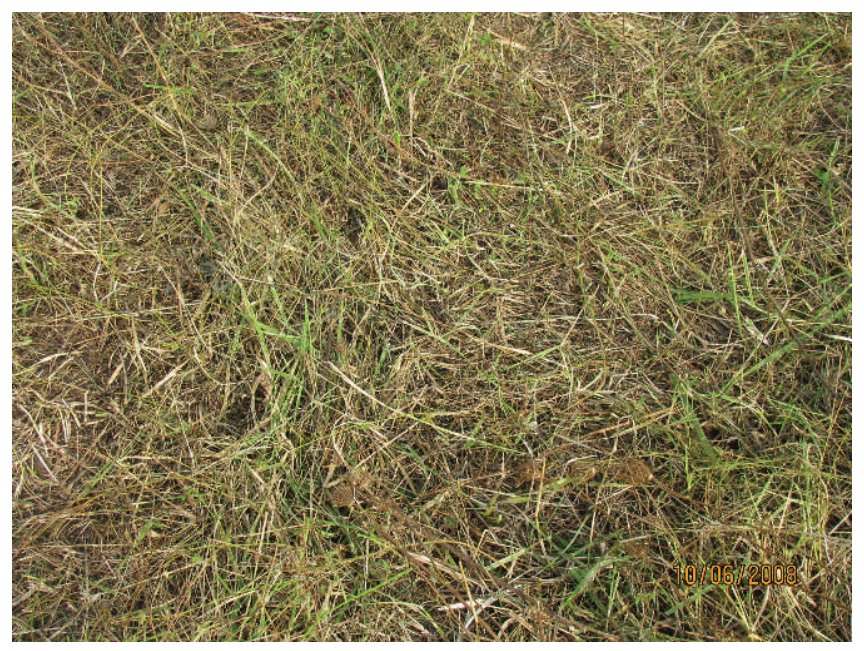

Figure 2. Residual remaining after 80,000 pounds per acre. It is virtually all stems and no leaves.
At any lower stocking density, there will still be some selective grazing taking place.

After implementing higher stocking densities, cows now graze, at some times of the year, just about every plant species in the pasture. At first, an insufficient forage allowance was suspected-starving them so much they wanted to eat the weeds. But monitoring behavior revealed that when first moved to their next forage allocation, some cows went straight to the sumac (Rhus glabra) or sericea (Lespedeza cuneata). It became obvious that these cows had developed either a taste, or a need, for some of these "weeds" that they wouldn't have grazed before they were in a high stocking density system, which had the added advantage of broadening the amount of forage available for livestock production.

Quality and palatability of forage species varies a great deal during the year and plays a significant role in what the animals eat at different times of the year, but it doesn't explain everything. During the same time of the year, the same herd of cattle grazing at 30,000 pounds per acre of stocking density totally avoid a plant like Missouri ironweed (Vernonia missourica; Fig. 3), but at stocking densities over 100,000 pounds per acre eat almost every leaf from the plant (Fig. 4). The photo in Figure 3 was taken a few days after grazing so the background appears greener than that in Figure 4, but

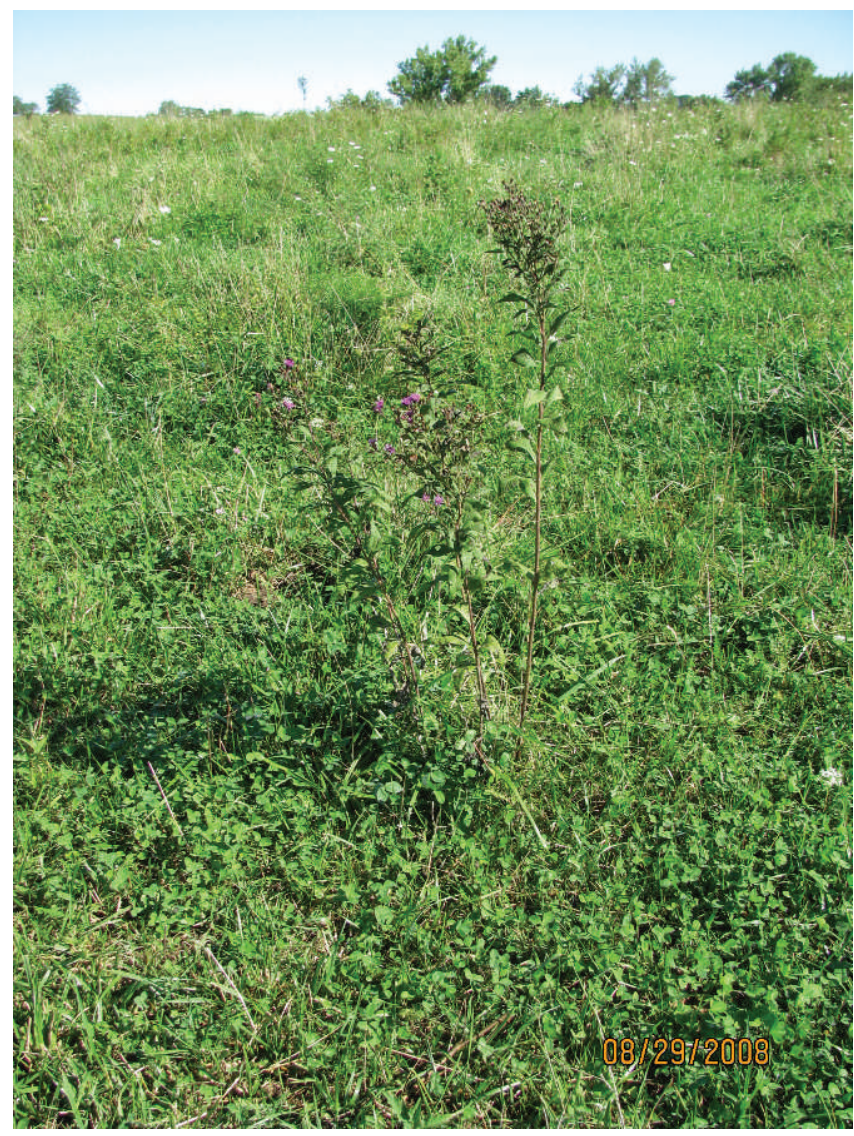

Figure 3. Missouri ironweed virtually untouched at 30,000 pounds per acre stocking density. 


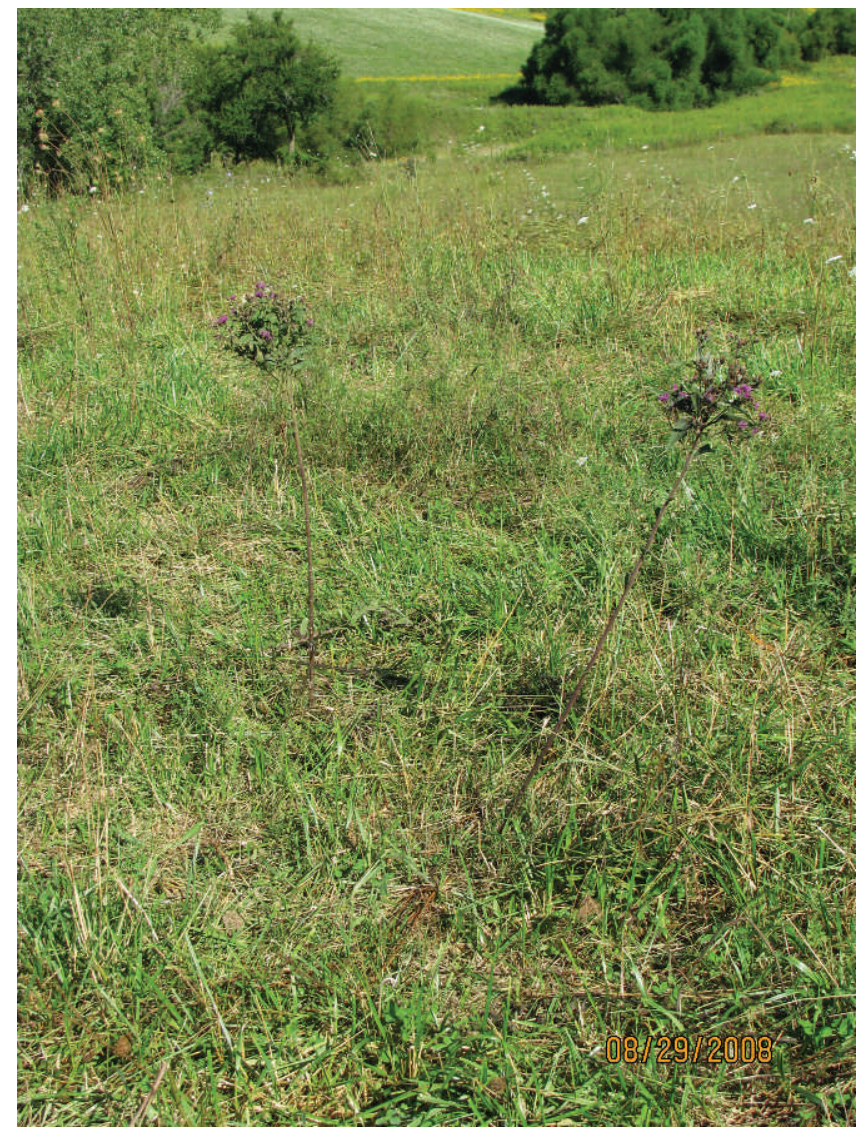

Figure 4. Missouri ironweed almost completely defoliated after being grazed at 120,000 pounds per acre stocking density.

the ironweed plants themselves remain unchanged since the grazing occurred.

\section{How Does Stocking Density Affect the Water Cycle and Mineral Cycle?}

The biggest benefit of higher stocking density is in the improvements we can make to the soil. The health of the soil drives everything. It doesn't matter whether you are in a 10 inch rainfall area or a 40 inch rainfall area; the health of the soil drives almost all environmental processes. Our management can have a direct impact on soil biological activity, mineral cycling, soil organic matter, and water infiltration into and evaporation from the soil surface.

Liebig's Law of the Minimum ${ }^{2}$ states that growth occurs only at the rate permitted by the most limiting factor. In many cases, water is the most limiting factor, even in a relatively wet environment like Missouri that receives 36-38 inches of yearly rainfall because many people do not do a good job of capturing and keeping it all. Most soils in the United States have lost a substantial part of their pre-European settlement soil organic matter (SOM). Soils that have been tilled for any length of time have likely lost three-fourths of their SOM. Even rangeland that hasn't been tilled but has been over grazed for decades has, in many cases, lost half of the SOM. This loss has had a huge impact on the water infiltration ca-

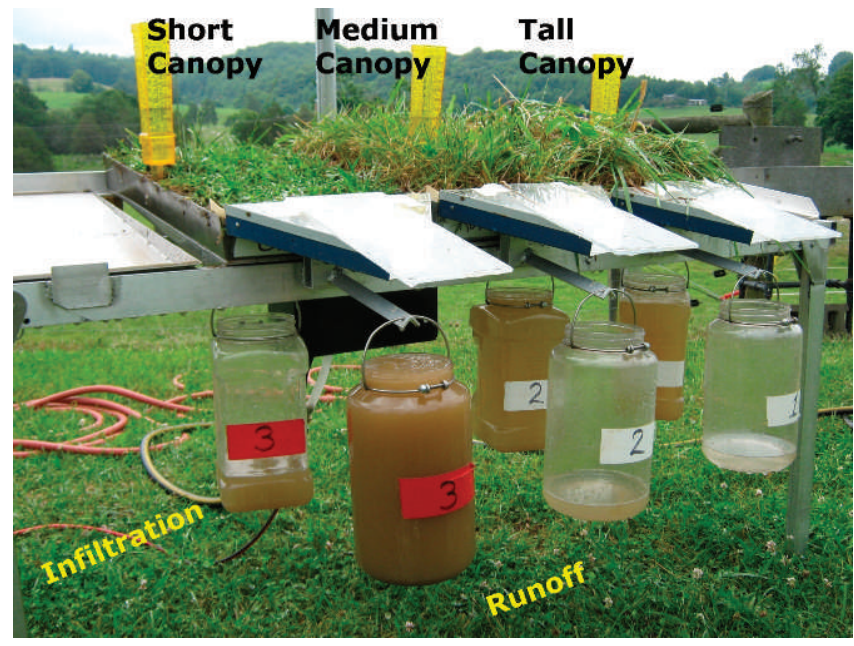

Figure 5. Rainfall simulator. Infiltration is much better in taller grass.

pabilities of the soil and ultimately the forage production of that soil.

In our environment, many MiG systems typically utilize a recovery time of 25-45 days. This keeps the plants in a fairly short vegetative state. Plant roots are typically a reflection of the above-ground biomass. Short tops mean short roots. By using longer recovery periods we allow a plant to nearly achieve its maximum above- and below-ground biomass. The tall canopy helps to reduce raindrop energy and increases infiltration. Plant roots are very effective at removing compaction in the soil.

When we keep a taller, thicker canopy of forage for a longer portion of the year we are keeping our soil cooler and reducing evaporation. Figure 5 shows how canopy height canopy height can have a positive effect on infiltration. Even in fields that have $100 \%$ ground cover we are seeing that a taller canopy can reduce summer soil temperatures by as much as 30 degrees Fahrenheit. We have known that ground cover was very important for a long time, but we didn't realize the importance of canopy height. We are actually creating a microclimate above the surface of the soil by having a tall canopy.

By using more intensive management and higher stocking density, we increase the uniformity of utilization of all the plants in a particular sward, which then allows us to build longer recovery periods into our rotations while maintaining the same stocking rate. Uniformity in one paddock does not mean that the entire landscape will be a monoculture of one forage type or at the same stage of recovery. By using high stock density we may have the equivalent of more than 100 paddocks or pastures spread out over the landscape. This means we will have a landscape in more than 100 different levels of recovery, and we will have a landscape with more than 100 types of wildlife habitat. By impacting all forage species in a paddock uniformly we actually control species that may otherwise dominate. Additionally, by varying the time of the year each paddock is grazed we can stimulate diversity even more. Longer rest periods, controlling dominant 
species, and varying the timing of our grazing events have led to an increase in many grazing-intolerant species of plants.

The soil is a living factory of macroscopic and microscopic workers who need food to eat and places to live to do their work. The number one food source of most soil microorganisms is a living root. In the case of soil microorganisms short plant tops mean a short roots but also a short food supply. Microbial food is exuded by plant roots to attract and feed microbes that provide nutrients at the root-soil interface where the plants can take them up. Allowing plants to reach their maximum above-ground biomass, and in turn their maximum root mass, will provide soil microorganisms with a food source that will allow them to function at a high level.

The longer recovery periods that we are building into our rotations allow plants to develop larger and deeper root systems that are capable of pulling minerals from depths not obtainable by plants kept in a shorter vegetative state. The long recovery periods are also more beneficial to the growing patterns of most tap-rooted forbs. The tap-rooted plants may not produce the volume of biomass that grasses do, but are crucial to effectively cycling minerals up and down through the soil profile as well as providing high-quality forage. At higher stocking densities, livestock trample and spread a portion of the forage that is not eaten into mulch on the surface of the soil. Depending on the environment, plants left standing can take months or even years to break down so that nutrients become available for the next plant to use. By putting some of the uneaten forage on the ground we speed up mineralization.

\section{Summary}

In our rangelands, stocking density, when properly managed by providing adequate forage for the animals and proper levels of recovery between graze periods, is one of the most powerful tools we have to manage our grassland/rangeland resources. By altering stocking densities a producer can achieve many different goals. Stocking densities can significantly affect livestock forage utilization, performance, and uniformity of grazing. Proper stocking density can also be used as a tool to increase utilization of typically unpalatable plant species, improve manure distribution, and make significant improvements in the mineral and water cycles.

\section{References}

1. Gerrish, J. 2004. Management-intensive grazing: the grassroots of grass farming. Ridgeland, MS, USA: Green Park Press. $314 \mathrm{p}$.

2. van der Ploeg, R. R., W. Böhm, and M. B. Kirkham. 1999. On the origin of the theory of mineral nutrition of plants and the law of the minimum. Soil Science Society of America Journal 63:1055-1062.

Authors are Rancher and State Soil Health Conservationist, NRCS, Ridgeway, MO 64481, USA, doug.peterson@mo.usda. gov (Peterson); Rancher, Brownlee Ranch, Lowry City, MO 64763, USA (Brownlee); and Rancher, Kelley Ranch, Elmo, MO 64445, USA (Kelley). 